(C) Nepal English Language Teachers' Association (NELTA)

ISSN: 2091-0487

\title{
Editorial
}

\section{Continuing the journey ...}

$\mathbf{W}$ e are delighted to bring you the latest issue of the Journal of NELTA (Issue 1 - 2, Volume 18) which has been instrumental in promoting scholarship and research on English language teaching (ELT) not only in Nepal but also in the wider ELT community in the world. As an open access journal, it reaches anyone who is interested in ELT and has access to the internet. The most recent (December 2013) statistics from the official site of the journal shows that the journal articles were downloaded 119,429 times since July 2010 (see the official site http:/ / www.nepjol.info/index.php/NELTA).

As you may have noticed, this combined issue of the journal is edited by a new editorial team of five ELT professionals, who are dispersed in four different countries and three continents. The new editorial team took over the responsibility of editing the journal in May 2013 from the previous team. The previous team did a remarkable job of making the journal an open access one and getting it indexed on various international research databases, thus making it highly visible on the web and among ELT researchers and practitioners. Building on the extensive and commendable work carried out by our predecessors, we expect to continue our journey to make the Journal of NELTA a premier open access ELT journal. However, the journey has not always been easy given our newness to the journal's publication and editorial system. Furthermore, the team had never worked together and most of us were new to the job. Of course, we did have a team spirit which kept us motivated and energetic during challenging times. The whole process has been collaborative and rewarding as we were able to understand ourselves better by self-critiquing and tapping into our skills, knowledge and experience to further the cause of NELTA and the journal.

We would like to note that the response to the call for papers regarding the current issue of the journal was overwhelming. We had received 46 full papers and peer-reviewing them was extremely demanding as we constantly 
needed to find new reviewers. The reason for this high response may have been our publicity of the call through various channels including professional mailing lists, our professional networks, NELTA website and widely used ELT websites such as the British Council's TeachingEnglish website in addition to our own dedicated website. This publicity provided us with good quality articles and we intend to continue this approach in future too.

Despite the challenges encountered during the editorial process, this issue, as previously, promotes NELTA's mission by making this journal a forum for enhancing ELT practices in Nepal and beyond. It brings scholarly and evidencebased papers together and addresses current issues and debates in ELT in Nepal and globally. As an indigenous publication, the journal celebrates local ELT practices and promotes teachers as a key changing agent in classroom practices. Thus, the journal aims to address and encourage dialogues on current issues in local ELT contexts. Some of these issues include introducing English as a foreign language in early years, multilingualism, critical perspectives on English language, the use of social media in ELT (disruptive or supportive technologies), critiquing established ELT theories and praxis due to the situatedness of one's ELT practice, alternative views on assessment and so on. We hope the articles in the current issue, a synopsis of which is presented below, touch upon most of these issues and contribute to expanding your repertoire of local ELT practices.

Two of the articles in this issue deal with the use of technology in ELT. The first one is by Sharda Acharya and Seemita Mohanty who investigate the use of social media (i.e., Facebook) by youths in India. They present an interesting and popular phenomenon among young adults who constantly use Facebook. Based on a survey, they argue that the English language young adults use in their Facebook communication may not necessarily enhance their English language skills. However, they mention that incidental learning can still occur. The second paper (Jeffrey Lee and Paul Sparks)explores the use of technology (e.g., the internet) by teachers and community in Bungamati, Kathmandu, Nepal. Following an ethnographic perspective, the authors studied aspects of technology integration into classrooms. They found that there were many challenges and hurdles which are linked with wider societal views of gender, teachers' perceptions of technologies and students' views about learning.

A critical perspective is presented by Neil Addison and Sovo Saha in their articles. While Addison critiques the use of ELT materials in Japan and questions their value in English as a foreign language (EFL) context such as Japan, Saha, using Norman Fairclough's critical discourse analysis, argues that English language learning guidebooks are produced purely for economic gains rather than any English language learning. The 
notions of colonialism, globalization and cultural criticism have also been examined in relation to the field of English language teaching in both the contexts. They explore the growing industrialized ideas of ELT due to socioeconomic values and several other related factors.

Two of the articles (Joshua Cohen and Tai Feng-Chen) in this issue focus on writing. It is notable that both of them discuss different aspects of writing among undergraduate students in two countries (Japan and Taiwan). While Cohen's paper examined the impact of topic selection on students' fluency of writing, Feng-Chen compared the extent of positive impact of two vocabulary learning approaches (productive and receptive) on student writing.

Learner autonomy is another area that is addressed in this issue. Natasa Gajst and Paunluck Puntahachart Saengsawang explore it in their articles. Gajst investigates the potential of learning autonomy and the use of authentic reading materials with undergraduate students taking business English courses in a European context. It examines how authentic materials such as business related newspaper articles could be used as autonomous study tools to enhance students' linguistic competence and general business terminologies. Saengsawang investigates the impact of Facebook integration into an English language course on learner autonomy and achievement of Thai university students. The results indicated both positive and negative effects. While the autonomy was positively affected, academic achievement was otherwise.

The other topic addressed in this issue is the role of English language in the multilingual context of Nepal. Ashok Raj Khati's article examines the perceptions of Nepalese English language professionals with regard to the value of English in promoting or hindering the development of local languages.

The value of form-focused guidance and task planning is explored in Suman Laudari's article. He compares an adult EFL learner's task performance with and without form-focused task guidance. He argues that form-focused pre-task guidance may enhance adult learners' accuracy while their fluency may be compromised.

The debate on English language assessment continues and Pratistha Shrestha contributes to this debate through her article that investigates alternative assessment practices in five English medium private schools in Kathmandu, Nepal. She uses teachers' written personal narratives as her research instrument which is innovative. Her study shows that various forms of formative assessment took place in these private schools, which is encouraging. Nonetheless, such practices may be far from real in the majority of the schools in Nepal for various reasons including 
the availability of resources, teachers' motivation and their skills and a systemic structure being in place (or otherwise).

In addition to the research articles described above, we also have a reflective article in this issue. In a Bangladeshi context, Farida and Sinha reflect on how they helped their first year undergraduate students dealing with literary materials, especially the ones who had very limited or no earlier exposure to literary texts. It outlines how teachers addressed the needs of such students to develop their critical and creative abilities through the use of teacher prepared materials.

All in all, the articles in this volume cover a wide range of issues and themes in ELT. Particularly, they promote local ELT practices not only from Nepal but also from many other countries. We expect that these articles will be of great interest to our readers.

Finally, we would like to extend our gratitude to both the authors and the reviewers who have been very supportive throughout the process. They responded to us promptly even when the deadline was extremely tight. We are equally grateful to the Central Committee of NELTA for their continuous support. We would like to thank our designer, Gambhir Man Kapali, who helped to present this volume so elegantly. As many of you may know, an online version of this journal is made available as an open access journal via Nepal Journal Online. We are grateful to Sioux Cumming who has been providing professional support to maintain the journal online. Last but not least, the editorial team and the NELTA Central Committee like to earnestly appreciate Ekata Publication's support for the publication of the print version of this volume.

Happy reading!

Prithvi N. Shrestha

Khagendra Raj Dhakal

Laxmi Prasad Ojha

Lal Bahadur Rana

Hima Rawal 